\title{
Manajemen Mengurangi Kecemasan dan Nyeri dalam Persalinan dengan Menggunakan Virtual Reality : A review
}

\author{
$\underline{\text { Intan Gumilang Pratiwi }{ }^{1} \text {, Herliana Riska }}{ }^{2}$, Kristinawati Kristinawati ${ }^{3}$ \\ ${ }^{1}$ Poltekkes Kemenkes Mataram \\ ${ }^{2}$ Universitas Padjadjaran Bandung \\ ${ }^{3}$ Akbid Panti Wilasa
}

Corresponding author: Intan Gumilang Pratiwi

Email: intangumil@gmail.com

Received: February $10^{\text {th }}, 2019$; Revised: February $25^{\text {th }}, 2019$; Accepted: April $11^{\text {th }}, 2019$

\begin{abstract}
Labor pain is a subjective experience experienced by the mother about physical sensations associated with uterine contractions, dilation and thinning of the cervix and decreased fetus during labor. Reaction to pain is a very individual response. The sensitivity of anxiety in labor pain has a significant relationship to sensory and affective pain in labor. Labor anxiety and pain significantly affect maternal labor, therefore various methods of pharmacological and non-pharmacological methods are carried out in an effort to deal with pain. Technology was also developed to support these non-pharmacological efforts. One of them uses virtual reality (VR) as the current and future trends for pain management. This scientific article is a literature review with a systematical review method from various literature which includes a systematic search study of computerized databases (PubMed, BMC, Cochrain review, Google Scholar) in the form of research journals and review articles related to virtual reality. The results of this literature study are virtual reality technology capable of reducing anxiety and being able to be used to reduce pain during labor.
\end{abstract}

Keyword: labor pain; anxiety; virtual reality

\section{Pendahuluan}

Proses persalinan merupakan pengalaman emosi dan melibatkan mekanisme fisik dan psikologi. Nyeri persalinan merupakan pengalaman subyektif yang dialami ibu tentang sensasi fisik yang terkait dengan kontraksi uterus, dilatasi dan penipisan serviks serta penurunan janin selama persalinan. Reaksi terhadap nyeri merupakan respons yang sifatnya sangat individual. Reaksi ini tergantung pada kepribadian, kondisi emosional serta tingkat pemahaman pasien, latar belakang kultural, keluarga serta pendidikannya, dan pengalaman sebelumnya. Sensititifitas kecemasan dalam nyeri persalinan mempunyai hubungan yang signifikan terhadap sensorik dan afektif pada nyeri persalinan. (Whitburn, Jones, Davey, \& Small, 2017)

Kecemasan ibu bersalin dalam jangka waktu yang panjang, menyebabkan system saraf autonom meningkatkan kontraksi otot polos dari sistem arteri. Hal ini kemudian mengurangi aliran darah uteroplasenta serta oksigenasi ke rahim, menyebabkan hipoksia janin, dan meningkatkan denyut jantung janin abnormal. Kecemasan dalam persalinan menyebabkan pelepasan kortisol yang mengakibatkan perpanjangan waktu persalinan, penurunan aliran darah ke plasenta dan menyebabkan hipoksia pada janin. Adanya perkembangan ilmu pengetahuan, maka dikembangkan beberapa metode untuk meminimalkan dan atau menghilangkan rasa nyeri saat persalinan. (Klomp, Jonge, Hutton, \& Lagrojanssen, 2013)

Rasa takut dan cemas merupakan faktor psikologis yang dianggap signifikan berpengaruh dalam rasa nyeri pada saat proses persalinan. Faktor psikologis berupa kecemasan menghadapi persalinan tersebut mempunyai konsekuensi jangka pendek dan jangka panjang pada keadaan kesehatan ibu dan janin. Selama beberapa dekade para ahli fokus untuk mengembangkan berbagai cara untuk mengatasi hal tersebut. Berbagai upaya 
dikembangkan untuk mengatasi nyeri pada ibu bersalin meskipun tidak semua dari metode tersebut efektif untuk mengurangi nyeri, mempunyai efek negatif dan mempunyai risiko yang tidak baik bagi keadaan ibu dan janin.(Whitburn et al., 2017)

Seiring dengan kemajuan jaman, upaya mengatasi nyeri melalui metode non farmakologis berbasis teknologi banyak dikembangkan. Salah satunya adalah penggunaan Virtual reality (VR). Virtual reality adalah suatu teknologi yang menghadirkan suatu realitas maya atau dunia virtual. Pengguna VR akan dihadapkan pada suatu pengalaman virtual berupa manipulasi lingkungan 3D yang immersive atau seolah olah nyata. Kombinasi teknologi head-mounted display (HMD), musik audio, joys stick maupun perangkat lain yang mendukung Virtual environment (VE) atau lingkungan virtual secara lengkap menghadirkan suatu multimodal sensorik (visual,auditori,taktil) yang berkontribusi sebagai pengalaman aktual yang dirasakan oleh seseorang, sehingga pengalaman yang didapatkan dari VR akan lebih baik daripada pengalaman pasif seperti menonton video atau melihat televisi.(Kenji et al., 2012; Li, Montaño, Chen, \& Gold, 2011; Rudarakanchana, Van Herzeele, Desender, \& Cheshire, 2015; Sharar \& Patterson, 2011; Smith \& Ericson, 2009; Tanja-dijkstra et al., 2014)

Pada awalnya VR hanya untuk kepentingan hiburan dan game. Namun semenjak sepuluh tahun yang lalu VR diaplikasikan pada area klinis untuk manajemen nyeri, rehabilitasi fisik, dan treatment untuk gangguan psikiatrik (phobia, gangguan stres post trauma, dan kecemasan). Pada area klinis VR lebih banyak digunakan pada melemahkan persepsi nyeri, kecemasan dan stres umum yang terjadi selama prosedur medis seperti perawatan luka bakar, kemoterapi, prosedur dental dan prosedur medis rutin lainnya. Beberapa teori diajukan untuk mendasari mekanisme kerja VR untuk mengurangi nyeri.Beberapa peneliti mempertimbangkan peranan penting interaksi biologis korteks dan neurokimia otak seperti emosi, kognitif dan proses perhatian yang secara efektif mampu mengurangi nyeri.

Melzack dan Wall dengan teori gerbang kontrol yang mengusulkan berbagai faktor yang terlibat dalam nyeri seperti perhatian terhadap nyeri, emosi yang terkait nyeri, dan pengalaman masa lalu yang terkait dengan nyeri memerankan peran penting dalam proses interpretasi nyeri. Mc Caul dan Mallot mengajukan teori bahwa kapasitas perhatian manusia terbatas dan individu harus menjauhkan diri atau mengalihkan perhatian dari stimulus nyeri agar nyeri berkurang. Wickens mengusulkan Multiple Resources Theory yang mengatakan bahwa dalam stimulus sensorik yang berbeda akan menghadirkan suatu stimulus yang mandiri. Hal ini mendukung sifat VR yang berdasar pada integrasi multimodal (visual, auditori, taktik maupun penciuman) untuk pengalihan.(Asl Aminabadi, Erfanparast, Sohrabi, Ghertasi Oskouei, \& Naghili, 2012; GutiérrezMaldonado, Gutiérrez-Martínez, Loreto-Quijada, \& Nieto-Luna, 2012; Hoffman et al., 2011; Keefe et al., 2012; Li et al., 2011; Morris, Grimmersomers, Spottiswoode, \& Louw, 2011; Patterson, Jensen, Wiechman, \& Sharar, 2013; Sharar \& Patterson, 2011; Tanja-dijkstra et al., 2014)

Berbagai penelitian telah dilakukan untuk menguji efektifitas VR dalam mengurangi nyeri. Hoffman dkk yang pertama kali melakukan penelitian penerapan VR pada pasien luka bakar. Hoffman membagi dua kelompok remaja yang menjalani perawatan luka bakar antara yang diberi pengalihan berupa VR dibandingkan dengan video game. Pada kelompok yang diberikan VR menunjukkan penurunan nyeri yang signifikan dibanding yang dialihkan dengan video game. Hoffman juga meneliti penggunaan VR untuk prosedur perawatan gigi. Pasien perawatan gigi dibagi tiga kelompok yaitu yang menggunakan VR, yang menggunakan film dan kelompok kontrol. Nyeri diukur dengan poin 1-10. Hasilnya didapatkan pada pasien yang tanpa intervensi atau kelompok kontrol pasien merasakan nyeri yang berat (mean: 7,2), pasien yang dialihkan dengan film merasakan nyeri ringan (mean:3,3) dan pada kelompok ketiga yang diberikan VR didapatkan hasil hampir tidak merasakan nyeri (mean: 0,6).(Kenji et al., 2012; Sharar \& Patterson, 2011; Tanja-dijkstra et al., 2014)

Bidan sebagai ujung tombak pelayanan kesehatan ibu dan anak di komunitas diharapkan dapat memberikan pelayanan dengan merespon pasien yang membutuhkan penanganan nyeri saat proses persalinan, sehingga diharapkan tercapai pelayanan persalinan yang berkualitas dengan demikian mampu menurunkan kecemasan serta nyeri ibu dalam menghadapi persalinan dalam upaya menurunkan angka kematian ibu. Tujuan dari penulisan ini adalah untuk melakukan studi literatur tentang virtual reality dalam menguragi kecemasan serta mengurangi nyeri dalam persalinan. 


\section{Metode Penelitian}

Studi ini merupakan suatu telaah jurnal (Literature Review) yang mencoba menggali manajemen terkini dalam rangka mengurangi kecemasan dalam persalinan dengan metode pengalihan dan membangun pengalaman serta pemahaman ibu tentang persalinan menggunakan virtual reality. Sumber untuk melakukan tinjauan literatur ini meliputi studi pencarian sistematis database terkomputerisasi (PubMed, BMC, Cochrain review, Google cendekia) berbentuk jurnal penelitian dan artikel review dalam 10 tahun terakhir. Penulisan artikel ilmiah ini menggunakan penulisan daftar pustaka vancouver.

\section{Hasil dan Pembahasan}

\section{Persalinan}

Persalinan normal adalah proses pengeluaran janin yang terjadi pada kehamilan cukup bulan (37-42 minggu) lahir spontan dengan presentasi belakang kepala yang berlangsung dalam 18 jam, tanpa komplikasi baik pada ibu maupun pada janin. Persalinan adalah proses fisiologis dimana janin dikeluarkan dari rahim ke dunia luar dan didefinisikan sebagai kontraksi uterus yang teratur disertai dengan penipisan serviks dan dilatasi. (Shrestha, 2013)

\section{Mekanisme kontraksi menyebabkan nyeri persalinan}

Permulaan nyeri persalinan pada kala I dimulai dengan peningkatan rangsangan nociceptor pada mekanikal dan kemoreseptor uterus dan serviks. Ambang nyeri yang tinggi mekanoreseptor diperoleh dari stimulasi akibat dari tekanan yang kuat dan terus menerus selama kontraksi uterus. Kerusakan mioseluler akibat dari kontraksi berulang di fase berikutnya, menghasilkan bradikinin, histamin, serotonin, asetilkolin, dan ion kalsium yang mengaktifkan nociceptor kimia.

\section{a. Jalur perifer}

Kala I persalinan. Nyeri pada kala I persalinan adalah akibat dari kontraksi uterus dan peregangan serviks. Secara alamiah hal ini terjadi seperti kram dan viseral, nyerinya menyebar dan sulit terlokalisasi. Sensasi nyeri dibawa oleh serabut aferen utama Ad dan C yang melewati secara berurutan melewati pleksus hipogastik inferior, tengah dan superior,

\section{b. Jalur perifer}

Kala I persalinan. Nyeri pada kala I persalinan adalah akibat dari kontraksi uterus dan peregangan serviks. Secara alamiah hal ini terjadi seperti kram dan viseral, nyerinya menyebar dan sulit terlokalisasi. Sensasi nyeri dibawa oleh serabut aferen utama Ad dan $\mathrm{C}$ yang melewati secara berurutan melewati pleksus hipogastik inferior, tengah dan superior, lumbal, dan cincin simpatis torak bawah dan berakhir di rami communicantes yang berhubungan dengan saraf spinal T10-L1. Sensasi nyeri ini dominan dibawa oleh serabut $\mathrm{C}$.

Selama akhir kala satu persalinan dan dimulainya kala kedua persalinan, nyeri somatik lebih dominan, akibat dari distensi dan penarikan pada struktur panggul, dasar panggul dan perineum. Dan nyeri ini dibawa melalui saraf pudenda melalui rami anterior S2 dan S4. Tidak seperti nyeri viseral pada kala I, nyeri somatik ini lebih tajam dan terlokasi dengan baik, terutama karena kurang arborisasi dan kecepatan konduksi yang lebih cepat di jalur sakral. Hal ini sebagian besar dibawa oleh serabut Ad.

\section{c. Jalur sentral}

Jalur sensasi persalinan berjalan setelah memasuki sistem saraf pusat meliputi jalur ascending dan jalur decending.

\section{1) Jalur Ascending}

Sinaps pertama pada jalur ascending, terjadi pada unsur abu-abu dorsal pada batang spinal (Rexed lamina I-V). Sebagian besar dari sinaps neuron aferen primer awalnya di lamina I dan II superfisial (substantia gelatinosa); secara lokal memproyeksikan interneuron yang pada gilirannya sinaps pada lokasi yang lebih dalam wide dynamic range (WDR: lamina $\mathrm{V}$ ) neuron. WDR neuron menerima input rangsang sinaptik baik dari mielin AA dan AA aferen mechanoreceptor dan $\mathrm{C}$ aferen nociceptive polimodal. Faktanya bahwa semua sel lamina $\mathrm{V}$ yang menanggapi ambang nyeri visceral yang tinggi juga yang menanggapi ambang nyeri rendah aferen kulit dari daerah kulit disuplai oleh segmen batang spina yang sama. Dengan demikian sel-sel lamina $\mathrm{V}$ memberikan dasar persyarafan untuk fenomena sakit yang dimaksud yang terjadi selama setiap kontraksi uterus.(Patel, 2010)

2) Jalur Descending

Jalur ini berasal dari korteks sensorik primer dan proyek ke unsur abu-abu peri aqueductal di otak tengah yang selanjutnya diarahkan ke inti ventral rostral di talamus. Proyeksi dari talamus memasuki tulang belakang melalui funiculus 
dorsilateral dan kembali lagi ke daerah abu-abu dorsal sumsum tulang belakang

Pada kala satu persalinan, nyeri timbul akibat pembukaan servik dan kontraksi uterus. Uterus berkontraksi karena dilatasi serviks dan penipisan. Iskemia uterus (penurunan aliran darah dan karena itu kekurangan oksigen) terjadi akibat dari kompresi arteri yang memasok miometrium selama kontraksi uterus. Impuls nyeri selama kala I persalinan ditransmisikan melalui T10 ke T12 dan L1 segmen saraf tulang belakang dan thoraks bawah dan saraf simpatis lumbal atas. Saraf ini berasal dari badan rahim dan leher rahim.

Rasa sakit dari distensi segmen bawah rahim, peregangan jaringan serviks karena penipisan dan pembukaan, tekanan dan traksi pada struktur yang berdekatan (misalnya, tuba uterus, ovarium, ligamen) dan saraf, dan iskemia rahim selama kala I persalinan adalah nyeri viseral. Nyeri ini terletak di atas bagian bawah perut. Nyeri dimaksud terjadi ketika rasa sakit yang berasal dari rahim menjalar ke dinding perut, daerah belakang lumbosakral, krista iliaka, daerah gluteal, paha, dan punggung bawah.

Selama kala II persalinan, wanita mengalami nyeri somatik, yang sering digambarkan sebagai nyeri yang intens, tajam, membakar, dan bersifat lokal. Nyeri ini berasal dari (1) distensi dan traksi pada dorongan peritoneum dan uteroservikal selama kontraksi; (2) tekanan terhadap kandung kemih dan rektum; (3) peregangan dan distensi jaringan perineal dan dasar panggul untuk memungkinkan bagian janin; (4) laserasi jaringan lunak (misalnya, leher rahim, vagina, dan perineum).

Model neurofisiologis mendefinisikan nyeri sebagai pesan sensoris trauma jaringan perifer yang khusus dan akurat dikodekan dalam saraf perifer, ditransmisikan dalam pusat jalur syaraf dan diterjemahkan dalam otak. Meningkatnya intensitas nyeri biasanya diamati dengan perkembangan dilatasi yang mungkin sebagian disebabkan ke ambang aktivasi diturunkan dalam mekanoreseptor dan stimulasi kemoreseptor yang dihasilkan oleh stimulasi berulang kontraksi rahim, rangsangan nociceptiptive dari fase dilatasi sebagian besar ditransmisikan ke akar ganglia posterior saraf di T10 melalui L1. (Patel, 2010)

\section{Virtual Reality untuk Mengurangi Kecemasan dan Nyeri Persalinan}

Virtual reality adalah teknologi baru sehingga seseorang berada di suatu lingkungan virtual sehingga orang tersebut merasa berada dalam dunia nyata,dan merupakan suatu lingkungan yang disimulasikan oleh komputer. Kebanyakan berupa pengalaman visual, ditampilkan di layar komputer atau lensa streoscopic display. Beberapa simulasi mengikutsertakan sensor informasi tambahan seperti suara melalui pengeras suara. Beberapa sistem yang sudah maju dilengkapi dengan efek tak terlihat namun dapat dirasakan, ini yang disebut force back. Pengguna dapat berinteraksi dengan lingkungan maya melalui perangkat input seperti keyboard dan mouse atau melalui perangkat eletronik lain seperti sarung tangan, bahu tangan virtual atau treadmill gerak putar.(Hoffman et al., 2011; Rudarakanchana et al., 2015; Sas, Reilly, \& O'Hare, 2011)

PenggunaanVR dalam mengurangi kecemasan dilakukan oleh riska dkk yang memberikan VR untuk membangun pengalaman dengan memberikan VR berupa video persalinan untuk membangun pengalaman melahirkan dalam rangka mengurangi kecemasan. dibagi menjadi 2 kelompok secara random, kelompok perlakuan mendapatkan dua kali VR, sedangkan kelompok kontrol mendapat pelayanan standar. Skor kecemasan dinilai menggunakan modifikasi Pregnancy-Related Anxiety Questionnaire (PRAQ), pemberian dilakukan sebelum dan sesudah perlakuan, untuk menilai penurunan skor kecemasan setelah pemberian VR yang kedua. ilai $\mathrm{p}$ pada penurunan skor kecemasan setelah perlakuan $<0,001$, dengan $\mathrm{RR} 2,178$, selang kepercayaan $95 \% \operatorname{IK}(1,356-6,172)$. Nilai median kecemasan sebelum perlakuan pada kelompok VR adalah 23. Nilai median kecemasan pada kelompok VR setelah perlakuan turun menjadi 14. Nilai median kecemasan sebelum perlakuan pada kelompok kontrol adalah 23,50. Nilai median kecemasan pada kelompok kontrol setelah perlakuan turun menjadi 18. Persen penrunan median pada kelompok VR adalah $36,4 \%$ sedangkan pada kelompok kontrol adalah 24,0\%.Ibu hamil yang tidak diberikan intervensi VR memiliki risiko kecemasan 2,89 kali lebih tinggi dibandingkan dengan kelompok VR.(Ganiem, 2019) 
Melzack dan Wall mengungkap teori gerbang kontrol yang mendasari prinsip VR mengalihkan nyeri, yang mengacu pada level perhatian pada nyeri, emosi yang berkaitan dengan nyeri dan pengalaman terakhir merasakan nyeri, semua hal tersebut mempunyai peranan bagaimana nyeri di interpretasikan. Teori gerbang kontrol menyatakan adanya mekanisme seperti gerbang di area dorsal horn pada spinal cord. Serabut saraf kecil pada reseptor nyeri "small nerve fibers" dan serabut saraf besar "large nerve fibers" bermuara di sel proyeksi yang membentuk jalur sphinothalamic menuju pusat saraf tertinggi (otak), dan sinyal dapat diperkuat atau diperlemah oleh inhibitoryintereuron. ${ }^{5}$ Mekanisme tersebut sebagai berikut, ketika tidak ada rangsangan nyeri inhibitory neuron mencegah projection neuron untuk mengirim sinyal ke otak sehingga dapat dikatakan gerbang tertutup atau tidak ada persepsi nyeri. Ketika rangsangan normal somatosensory (sentuhan,suhu dll) terjadi maka rangsangan akan dihantarkan ke serabut saraf besar, hal ini menyebabkan inhibitory neuron dan projection neuron aktif. Tetapi inhibitor neuron mencegah projection neuron untuk mengirim sinyal ke otak sehingga gerbang masih tertutup dan tidak ada persepsi nyeri. Ketika nociceptive (rangsangan nyeri) muncul rangsangan akan melalui serabut saraf kecil dan ini menyebabkan inhibitor neuron menjadi tidak aktif dan projection neuron mengirimkan sinyal ke otak sehingga gerbang terbuka dan persepsi nyeri muncul. Jadi bisa disimpulkan pada saat stimulasi nyeri terjadi (membuat gerbang terbuka), stimulasi pada serabut saraf besar dapat menghambat nyeri karena menyebabkan gerbang tertutup. (Kenji et al., 2012)

Demikian juga dengan hasil penelitian dari Patterson dkk yang pertama kali mengembangkan VR untuk mengurangi cemas dan nyeri pada pasien luka bakar selama perawatan luka. Penelitian case series ini melibatkan 13 pasien menggunakan VR distraksi berupa lingkungan virtual 3D berupa lingkungan salju. Konstantos dkk mengembangkan VR relaksasi menggunakan pemandangan virtual alam yang tenang untuk relaksasi. Hasil dari penelitian ini adalah nyeri turun pada menit ketiga pemberian VR pada kelompok intervensi. (Patterson et al., 2013)

Virtual reality dalam dunia kebidanan dilakukan oleh Najid dkk yang menggunakan VR untuk pasien yang dilakukan penjahitan episiotomy pada 30 pasien primigravida. Hasil dari penelitian ini adalah VR mampu mengurangi nyeri Selama penjahitan episiotomy secara significan dengan nilai $\mathrm{p}=0,038$. Najid mengungkapkan bahwa VR merupakan implementasi dari gate control teori dalam pengalihan nyeri. Ketika perhatian manusia terbatas maka nyeri dapat dialihkan. (Jahanishoorab, 2015)

Penelitian yang dilakukan pada tahun 2000 Hofman dkk menguji efektifitas VR dibandingkan video standar pada dua remaja (16 dan 17 tahun) yang menjalani perawatan luka bakar. Hasilnya VR mampu mengurangi tingkat nyeri, kecemasan, dan waktu habisnya rasa nyeri. Demikian juga Das dkk memulai penelitian randomized control trial dengan membandingkan perawatan standar dengan analgesia dengan perawatan standar analgesia plus VR pada anak anak (5-18 tahun) selama menjalani luka bakar. Analgesia dengan VR lebih efektif untuk mengurangi nyeri dan stres dibandingkan dengan analgesia saja

Penelitian Intan dkk menyebutkan pemberian virtual reality yang diberikan berupa pengalihan saat persalinan dengan mengunakan pemandangan alam dll dengan 30 sampel pada saat kala I persalinan terbukti berhasil mengurangi nyeri persalinan sebanyak $20 \%$ aspek ini masih rendah karena nyeri tidak dapat dihilangkan secara keseluruhan hal ini dikarenakan banyak faktor yang megakibatkan nyeri. Hal ini juga dikarenakan aspek pengalihan belum maksimal, pada saat penelitian video pengalihan yang disediakan peneliti hanya lima video yang belum tentu cocok pada penerimaan subjek. Selain hal tersebut aspek nyeri sebagai sesuatu yang fisiologis tidak dapat dihilangkan secara keseluruhan, intensitas nyeri persalinan meningkat dengan dilatasi serviks yang lebih besar dan berkorelasi baik dengan intensitas, durasi dan frekuensi kontraksi rahim. Makin lama nyeri yang dirasakan akan bertambah kuat, puncak nyeri akan terjadi pada fase aktif pada saat pembukaan lengkap $10 \mathrm{~cm}$. Sehingga VR dapat digunakan untuk mengurangi nyeri saat persalinan pada saat fase persalinan tertentu. (Pratiwi, Husin, Ganiem, Susiarno, \& Arifin, 2017)

\section{Simpulan}

Dari berbagai studi literature diatas dapat disimpulkan bahwa VR dapat digunakan untuk mengurangi kecemasan dalam menghadapi persalinan serta mengurangi nyeri selama persalinan. 


\section{Daftar Pustaka}

Asl Aminabadi, N., Erfanparast, L., Sohrabi, A., Ghertasi Oskouei, S., \& Naghili, A. (2012). The Impact of Virtual Reality Distraction on Pain and Anxiety during Dental Treatment in 4-6 Year-Old Children: a Randomized Controlled Clinical Trial. Journal of Dental Research, Dental Clinics, Dental Prospects, 6(4), $117-124$ https://doi.org/10.5681/joddd.2012.025

Ganiem, H. R. B. H. P. A. R. (2019). JURNAL KESEHATAN PRIMA http://jkp.poltekkesmataram.ac.id/index.php/home/index, 13(1), 25-31.

Gutiérrez-Maldonado, J., Gutiérrez-Martínez, O., Loreto-Quijada, D., \& Nieto-Luna, R. (2012). The use of virtual reality for coping with pain with healthy participants. Psicothema, 24(4), 516-522. Retrieved from http://www.ncbi.nlm.nih.gov/pubmed/23079 345

Hoffman, H. G., Chambers, G. T., Iii, W. J. M., Arceneaux, L. L., Russell, W. J., Seibel, E. J., ... Patterson, D. R. (2011). Virtual Reality as an Adjunctive Nonpharmacologic Analgesic for Acute Burn Pain During Medical Procedures. https://doi.org/10.1007/s12160-010-9248-7

Hoffman, H. G., Patterson, D. R., Carrougher, G. J., Nakamura, D., Moore, M., GarciaPalacios, A., \& Furness III, T. a. (2001). The Effectiveness of Virtual Reality Pain Control With Multiple Treatments of Longer Durations: A Case Study. International Journal of Human-Computer Interaction, 13(1), $1-12$. https://doi.org/10.1207/S15327590IJHC130 $1 \_1$

Jahanishoorab, N. (2015). The Effect of Virtual Reality on Pain in Primiparity Women during Episiotomy Repair: A Randomize Clinical Trial, 40(3).

Keefe, F. J., Huling, D. A., Coggins, M. J., Keefe, D. F., Rosenthal, Z. M., Herr, N. R., \& Hoffman, H. G. (2012). Virtual reality for persistent pain: A new direction for behavioral pain management. Pain, 153(11), 2163-2166.

https://doi.org/10.1016/j.pain.2012.05.030

Kenji, S., Daniel, O., Kiyoshi, M., Satoshi, F., Kantaro, M., \& Akio, G. (2012). A novel application of virtual reality for pain control; virtual reality-mirror visual feedback therapy. Pain in Perspective, 237-254.

Klomp, T., Jonge, A. De, Hutton, E. K., \& Lagrojanssen, A. L. M. (2013). Dutch women in midwife-led care at the onset of labour: which pain relief do they prefer and what do they use?

Li, A., Montaño, Z., Chen, V. J., \& Gold, J. I. (2011). Virtual reality and pain management: current trends and future directions. Pain, 1(2), 147-157. https://doi.org/10.2217/pmt.10.15.Virtual

Melzack, R., \& Wall, P. (1965). Pain Mechanism: A new Theory. Science. https://doi.org/10.1126/science.150.3699.97 1

Morris, L. D., Grimmer-somers, K. A., Spottiswoode, B., \& Louw, Q. A. (2011). Virtual reality exposure therapy as treatment for pain catastrophizing in fibromyalgia patients : proof-of-concept study ( Study Protocol ). BMC Musculoskeletal Disorders, 12(1), 85. https://doi.org/10.1186/14712474-12-85

Patel, N. B. (2010). Chapter 3 Physiology of Pain Physiology of pain Central pain pathways e spinothalamic pathway and the trigeminal pathway.

Patterson, D. R., Jensen, M. P., Wiechman, S. A., \& Sharar, S. R. (2013). VIRTUAL REALITY HYPNOSIS FOR PAIN ASSOCIATED WITH, 58(3), 1-10. https://doi.org/10.1080/00207141003760595 .VIRTUAL

Pratiwi, I. G., Husin, F., Ganiem, A. R., Susiarno, H., \& Arifin, A. (2017). The Effect of Virtual Reality on Pain in Primiparity Women. International Journal of Nursing and Health Science, 4(February 2018), 4650.

Rudarakanchana, N., Van Herzeele, I., Desender, L., \& Cheshire, N. J. W. (2015). Virtual reality simulation for the optimization of endovascular procedures: current perspectives. Vascular Health and Risk Management, 11, 195-202. https://doi.org/10.2147/VHRM.S46194

Sas, C., Reilly, R., \& O’Hare, G. (2001). Virtual Reality in Surgery: Between Satisfaction and Stress, (Satava 1995), 99-111. Retrieved from http://eprints.lancs.ac.uk/42347/

Sharar, S. A. M. R., \& Patterson, D. R. (2011). 
VIRTUAL REALITY HYPNOSIS FOR PAIN CONTROL IN A, 28(2), 142-147.

Shrestha, I. (2013). Factors Influencing Perception 8(1), 26-30.

Smith, S., \& Ericson, Æ. E. (2009). Using immersive game-based virtual reality to teach fire-safety skills to children, 87-99. https://doi.org/10.1007/s10055-009-0113-6

Tanja-dijkstra, K., Pahl, S., White, M. P., Andrade, J., May, J., Stone, R. J., ... Moles, D. R. (2014). Can virtual nature improve patient of Labor Pain among Parturient Women at Tribhuvan University Teaching Hospital,

experiences and memories of dental treatment? A study protocol for a randomized controlled trial, 1-9.

Whitburn, L. Y., Jones, L. E., Davey, M., \& Small, R. (2017). The meaning of labour pain : how the social environment and other contextual factors shape women' $\mathrm{s}$ experiences, 1-11. https://doi.org/10.1186/s12884-017-1343-3 